\title{
Os arranjos familiares importam no momento de decidir em qual rede de ensino matricular os filhos?*
}

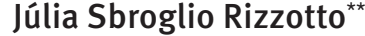 \\ Marco Túlio Aniceto França ${ }^{\star \star \star}$ \\ Gustavo Saraiva Frio ${ }^{\star \star \star \star}$
}

\begin{abstract}
0 presente trabalho tem como objetivo analisar se os arranjos familiares (monoparentais ou biparentais) afetam na escolha parental de qual rede de ensino (pública ou privada) matricular os filhos. Utilizando os dados da Pesquisa Nacional por Amostra de Domicílios (PNAD) de 2015, os resultados apontaram para dissemelhanças entre os arranjos familiares, as quais podem ser explicadas pelas diferenças nas preferências dos indivíduos, assim como na renda familiar. Verifica-se que existe maior probabilidade de as famílias investirem privadamente no ensino infantil. A evidência pode ser decorrente da oferta reduzida de creches públicas. Segundo a ordem de nascimento, para os arranjos familiares monoparental feminino e casal com filhos, as famílias preferem investir no filho mais velho, em detrimento dos demais filhos. Além disso, verificou-se que o filho do sexo masculino tem menores chances de estudar em uma rede privada caso esteja em um arranjo monoparental feminino. Esse resultado pode mostrar uma preferência da mãe em incentivar o estudo da filha em uma tentativa de empoderá-la.
\end{abstract}

Palavras chave: Arranjos familiares. Rede de ensino. Logit. Ordem de nascimento.

\footnotetext{
* Os autores agradecem ao comitê editorial da Rebep e a dois pareceristas anônimos pelas valiosas contribuições. 0 presente trabalho foi realizado com apoio da Coordenação de Aperfeiçoamento de Pessoal Nivel Superior - Brasil (Capes) - Código de Financiamento 001. Erros e omissões são de responsabilidade dos autores.

** Pontifícia Universidade Católica do Rio Grande do Sul (PUCRS), Porto Alegre-RS, Brasil (juliasbroglio@gmail.com; https:// orcid.org/0000-0002-8686-6619).

*** Pontifícia Universidade Católica do Rio Grande do Sul (PUCRS), Porto Alegre-RS, Brasil (marco.franca@pucrs.br; https:// orcid.org/0000-0003-1865-323X).

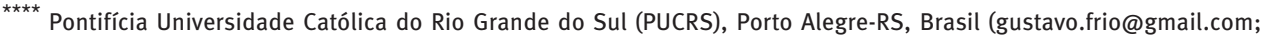
https://orcid.org/0000-0001-6453-312X).
} 


\section{Introdução}

Os arranjos familiares tradicionais vêm declinando gradativamente no mundo ocidental, inclusive no Brasil (MINAMIGUCHI, 2017; MEDEIROS; OSORIO, 2002). No estudo que compara as tendências demográficas no período 1940-2000, o Instituto Brasileiro de Geografia e Estatística (IBGE, 2007) mostrou que a família tradicional constituída por casal com filhos reduziu-se de $61,9 \%$ no Censo de 1970 para 49,4\% no Censo de 2010 . Alves e Cavenaghi (2012) ressaltam que esse novo contexto deve-se à queda na fecundidade, ao aumento na esperança de vida ao nascer e ao número de separações.

As famílias monoparentais femininas, ou seja, aquelas em que os filhos residem apenas com suas mães, são o segundo maior tipo de arranjo familiar no Censo de 2010, com $12,2 \%$, contra 7,9\% em 1970. Esse tipo de arranjo, em média, tem um nível socioeconômico inferior se comparado com os arranjos formados por casais. Além disso, tais famílias habitam domicílios que possuem um menor número de dormitórios e renda per capita menor. Lavinas e Nicoll (2006) apontam o elevado percentual de famílias nesse tipo de arranjo situado nos menores decis de renda. Rivas, Jociles e Moncó (2011) ressaltam que o arranjo monoparental feminino pode ser devido às preferências das mulheres em torno de uma percepção própria que esteja relacionada ao empoderamento e à autonomia. Ainda de acordo com o Censo, as famílias monoparentais masculinas passaram de 1,5\%, em 1970, para 1,8\%, em 2010. Adicionalmente, os dados do IBGE apontaram para o aumento da proporção de mulheres que chefiam domicílios entre 1981 e 2011: a porcentagem saltou de $16,9 \%$ para $37,5 \%$.

Esse fato pode se tornar relevante para desenhar políticas públicas, pois, de acordo com Barros et al. (1997), tanto nos países desenvolvidos como naqueles em desenvolvimento, as famílias cujo responsável é feminino possuem características demográficas, sociológicas e microeconômicas diferentes daquelas com responsável masculino. Segundo Thomas (1994), no Brasil, os pais e as mães alocam de formas diferentes os recursos familiares entre os filhos: enquanto as mães beneficiam as filhas, os pais direcionam os recursos para os filhos.

De acordo com Becker (1993), a renda e as preferências familiares (dentre elas, o número de filhos) impactam os determinantes dos investimentos em cada criança, uma vez que o custo de se investir nelas é afetado por suas características e habilidades naturais. Dessa forma, as escolhas parentais de educação podem acarretar problemas de estratificação educacional que seriam gerados pelas desigualdades na qualidade de ensino, cujos resultados podem perdurar entre as próximas gerações (ALVES, 2010; FERREIRA, 2001; GLOMM, 1997).

O conceito de capital cultural criado por Bourdieu (1992) visava suprir as desigualdades de desempenho escolar advindas de crianças com classes sociais diferentes. De acordo com o autor, o capital cultural pode existir em três estados: incorporado (que é o componente do contexto familiar que atua de forma mais marcante na definição do futuro 
escolar das crianças); objetivado (na forma de bens culturais); e institucionalizado (na forma de títulos escolares).

Coleman (1988) define o capital econômico como a renda e a riqueza material em termos de bens e serviços a que ele dá acesso. Para o autor, esse capital está associado ao contexto familiar que influencia o desenvolvimento da criança. Portanto, espera-se que as famílias com maior capital econômico proporcionem aos seus filhos acesso a instituições de ensino de qualidade mais elevada.

Coleman (1988) aponta a importância do capital social dentro da família para a educação dos filhos. Caracterizada pelas relações intrafamiliares, o capital social tem impacto na criação de capital humano intergeracional. De acordo com o autor, é possível que existam lares com alto capital humano (elevada escolaridade dos pais), porém não o traduzem em bom rendimento escolar dos filhos, dado que o capital social (a relação pais e filhos) é muito frágil.

Menezes-Filho e Pazello (2004) destacam que a qualidade educacional recebida pelas crianças no Brasil é distinta. Aquelas que estão matriculadas no sistema público acessam, em média, unidades escolares de qualidade inferior quando comparadas às escolas privadas. Embora os retornos educacionais sejam elevados e o acesso ao primeiro ano escolar seja quase universal, as crianças de famílias mais pobres tendem a abandonar os estudos antes da sua conclusão, devido aos baixos incentivos a permanecer na escola.

O objetivo do artigo é analisar se os arranjos familiares afetam a probabilidade de matricular os filhos em um tipo de rede de ensino em detrimento de outro. Além disso, consideramos se as chances se modificam de acordo com o nível de ensino, o sexo e a ordem de nascimento da criança, pois os investimentos parentais podem ser diferentes segundo as suas preferências. Para isso, a estratégia empírica é o uso do modelo logit e a fonte dos dados é a Pesquisa Nacional por Amostra de Domicílios (PNAD) de 2015. Cabe destacar que esta é a última PNAD regular divulgada pelo IBGE. Em 2016, os dados foram divulgados por meio da PNAD contínua que passou a substituir a PNAD regular.

Os principais resultados mostram que $14,88 \%$ das crianças e jovens da amostra selecionada para este estudo viviam em arranjos monoparentais femininos. Essa configuração familiar está em residências menores, com renda per capita inferior aos demais arranjos e nelas há uma maior propensão a investir privadamente na educação das meninas. Nos domicílios com casais e filhos ou nos monoparentais femininos, os filhos mais velhos têm maior probabilidade de estarem matriculados em escolas privadas em relação aos seus irmãos mais jovens.

Além disso, os pais têm maior propensão a gastar em educação infantil do que em ensino fundamental, pois estão mais propensos a pagarem a matrícula em uma escola privada. Esse resultado pode ser ocasionado pela falta de creches públicas, o que afetaria os arranjos monoparentais em proporções maiores do que os arranjos com ambos os pais presentes, dado o aumento no custo de entrada no mercado de trabalho. 
A contribuição do presente estudo está em considerar os arranjos familiares na questão educacional. A transição demográfica tem reduzido o número de filhos por família e esse aspecto gerará, no futuro, readequação no número de escolas e remanejamento de professores. Além disso, a diversidade da organização familiar, uma vez que o arranjo tradicional (casal com filhos) tem se reduzido em relevância, aponta para novas necessidades, entre elas, o aumento da oferta de creches e educação infantil, permitindo que a mulher chefe de família em um arranjo monoparental feminino possa ofertar trabalho. 0 crescimento no número de arranjos monoparentais masculinos também pode exigir modificações na política pública, no sentido de dar ao homem condições de cuidar da prole.

A seguir é realizada uma revisão de literatura sobre os modelos intrafamiliares de recursos. Posteriormente, abordam-se a fonte dos dados, as estatísticas descritivas e a estratégia empírica. Por fim são discutidos os resultados e tecidas as considerações finais.

\section{Alocação intrafamiliar de recursos aos filhos}

Ginther e Pollak (2004) ressaltam que dois fatores afetam o investimento nos filhos: o processo de alocação intrafamiliar de recursos; e a função de produção familiar, que relaciona os investimentos na criança com os rendimentos futuros desse investimento, sendo que essa função é estabelecida por insumos subjetivos (amor, atenção) e objetivos (tempo e dinheiro).

De acordo com a teoria econômica tradicional, a família investirá na criança até que o retorno marginal do investimento se iguale ao custo marginal do mesmo, quando o processo de escolha familiar não possui restrições. No entanto, Morduch (2000) afirma que as escolhas familiares enfrentam restrições orçamentárias e a família deve optar em como alocar os recursos disponíveis entre as diversas despesas, incluindo os gastos com os filhos.

Quanto à preferência dos pais para a determinação dos gastos com os filhos, Lloyd e Blanc (1996) apontam que, em consequência de as preferências não serem similares entre pessoas de sexos diferentes, é esperado que a alocação de recursos seja distinta, de acordo com o sexo do responsável pela família. Ademais, Hoddinott, Haddad e Alderman (1997) identificam que há diferença na alocação de recursos dado o sexo do responsável pela família. Ao isolar o efeito da renda relacionada aos homens, os autores verificaram que é gasta uma parcela maior da renda para bens de consumo pessoal se comparado com as mulheres. Entretanto, quando se consideram as mulheres, observa-se que elas são mais propensas a comprar produtos para crianças e consumo doméstico em geral. Macedo (2008) afirma que esse comportamento resulta em melhorias nos níveis nutricionais e nos cuidados de saúde e educação dos membros da família. Consequentemente, embora o volume de recursos possa se mostrar menor, na média, pode ter maior eficiência do ponto de vista familiar.

Independentemente do sexo do responsável pelo domicílio, antes de determinar o volume de recursos destinado aos filhos, as famílias devem decidir quantos filhos irão ter. 
Assim, cada família decide a quantidade de filhos, $n$, a partir da maximização da função utilidade $(U)$, que é composta pela quantidade de outras mercadorias agregadas no vetor X (BECKER; LEWIS, 1973; BECKER, 1993):

$U=U(n, X)$

A função de utilidade familiar é maximizada sujeita à restrição orçamentária da família. Os custos de produzir e educar as crianças são diferentes entre as famílias, visto que as funções de tempo e de produção familiar se diferem. Como as crianças são criadas com bens e serviços disponíveis no mercado aos preços $\pi_{X}$ e com o tempo dos pais a preço $p_{n}$, a restrição orçamentária é dada por:

$p_{n} n+\pi_{X} X=Y$

Para Becker (1993), a demanda por filhos depende, portanto, do preço relativo da criança e da renda:

$\frac{\frac{\partial U}{\partial n}}{\frac{\partial U}{\partial X}}=\frac{p_{n}}{\pi_{x}}$

Incluindo o custo para a realização de investimentos na criança na função de utilidade familiar, cada família maximiza sua função composta pela quantidade de crianças, $n$, e o gasto em cada criança, chamado de qualidade da criança $q$, e a quantidade de outras mercadorias $x_{n}$ (BECKER, 1993):

$U=U\left(n, q, x_{1}, \mathrm{x}_{2}, \ldots, x_{n}\right)$

Além dos preços dos bens e serviços disponíveis no mercado a preços $\pi_{X}$, a restrição orçamentária contém o custo que é constante para cada família de uma unidade de qualidade $p_{c}$ :

$p_{c} q n+\pi_{x} X=Y$

Sendo a multiplicação entre $q$ e $n$, na equação (2b), não linear, existe um trade-off na escolha familiar entre o número de filhos e o volume financeiro a ser investido neles. Assim, para ter equilíbrio na decisão da quantidade de filhos por família sujeito à restrição orçamentária, é preciso que:

$\left\{\begin{array}{l}\partial U / \partial n=\lambda p_{c} q \\ \partial U / \partial q=\lambda p_{c} n \\ \partial U / \partial q=\lambda \pi_{x}\end{array}\right.$

Apesar de os investimentos em educação dos filhos não serem substitutos diretos, eles são positivamente sensíveis ao aumento da renda e, em geral, estão negativamente relacionados com o número de filhos da família. Essa relação é explicada por meio da interação entre a quantidade e a qualidade, determinada pela substituição entre $q$ e $n$ na função utilidade (BECKER, 1993).

De acordo com Marteleto (2002), famílias menores podem aumentar as chances de elevar o investimento educacional para cada um dos filhos. A relação inversa entre tamanho 
da família e escolaridade dos filhos nos países desenvolvidos pode ser explicada pela hipótese de diluição de recursos (diluition of resources hypothesis) e de rivalidade entre irmãos (siblings' rivalry). Segundo essas teorias, os recursos destinados a cada filho diminuem com o aumento do número de crianças.

Os investimentos destinados a cada filho dependem da qualidade de cada criança, que é essencial para determinar a taxa de retorno desses investimentos, além de depender do número de filhos. Para Becker (1993), a taxa de retorno dos investimentos em capital humano dos filhos apresenta retorno decrescente, além de depender das características intrínsecas aos mesmos. Sendo assim, ainda que tenham os mesmos pais biológicos, as crianças possuem características pessoais diferentes, permitindo distintas taxas de retorno sobre os investimentos realizados em capital humano dos irmãos. De acordo com Breen Jonsson (2005), a decisão de escolha sobre a educação não é apenas dos pais, mas também do estudante baseado nos benefícios esperados vis-à-vis os custos inerentes e na probabilidade de sucesso nas diferentes opções educacionais.

Logo, a família que tem mais de um filho, ao decidir sobre o volume de investimentos destinado a cada um deles, enfrenta um trade-offentre eficiência de seus investimentos e equidade entre os filhos, uma vez que o volume a ser investido em capital humano depende tanto da disponibilidade de recursos como da taxa de retorno desses investimentos. A alocação intrafamiliar de recursos aos filhos só pode ser simultaneamente igualitária e eficiente se os filhos apresentarem as mesmas taxas de retorno aos investimentos (GUSTAFSSON; STAFFORD, 1997).

Como as famílias podem diferenciar a alocação de recursos entre os filhos no presente, estudos como os de Behrman et al. (1986), Becker (1993) e Kingdon (2005) procuram observar se essa discriminação apresenta ou não algum padrão. Behrman et al. (1986) buscaram identificar se há discriminação de gênero no investimento dos filhos nas famílias norte-americanas, sabendo que os rendimentos futuros femininos são menores do que os masculinos em muitas sociedades. Utilizando o modelo de ganhos intransferíveis e separáveis (SET), ${ }^{1}$ os autores não encontraram evidências estatisticamente significantes de que há favorecimento para os filhos por parte dos pais na alocação; pelo contrário, eles verificaram que, em algumas situações, os pais decidem por alocações igualitárias entre os filhos ou alocações que beneficiam as filhas.

Segundo Becker (1993), nas sociedades mais pobres existe uma discriminação na alocação de recursos entre os filhos, preferindo-se investir mais em educação dos filhos em detrimento das filhas. No entanto, essa diferença no investimento não ocorre, segundo o autor, devido às preferências familiares, mas sim porque os filhos apresentam taxas de retorno maiores do que as filhas. Kingdon (2005) encontrou evidências de que os resultados educacionais são significativamente piores para as meninas em comparação com os meninos, nos domicílios indianos em 1994. Além disso, as despesas familiares com a educação de meninas também são significativamente menores em comparação aos meninos. Kingdon

\footnotetext{
${ }^{1}$ Do inglês, Separable Earnings-Transfers (SET)
} 
(2005) apontou dois possíveis motivos: preferência dos pais por meninos; ou diferentes taxas de retorno dos investimentos.

Thomas (1994), Emerson e Souza (2002) e Carvalho e Kassouf (2009) testaram se há um viés de gênero na alocação intrafamiliar de recursos no Brasil. Emerson e Souza (2002) apontaram indícios de que a renda não laboral tanto do pai quanto da mãe não altera a probabilidade de frequência escolar das filhas, mas altera de forma positiva a probabilidade de frequência escolar dos filhos, o que indica uma discriminação de recursos com benefício aos meninos. Os autores estimaram um modelo probit com dados da PNAD de 1996.

Thomas (1994) observou que, no Brasil, os pais e as mães alocam de forma diferente os recursos familiares entre os filhos. As mães beneficiam as filhas e os pais os filhos. Para a análise o autor estimou um modelo de mínimos quadrados ordinários com dados do Estudo Nacional de Despesa Familiar (Endef) de 1974 e 1986. Ainda segundo Thomas (1994), as decisões intrafamiliares se baseiam no modelo não unitário ${ }^{2}$ e o sexo da pessoa que detém a renda é determinante para alterar o padrão de gastos familiares. Carvalho e Kassouf (2009), por meio dos dados da Pesquisa de Orçamentos Familiares (POF) 20022003, tentaram identificar se a composição de sexo entre irmãos altera as despesas familiares com educação no Brasil, não encontrando evidências estatisticamente significativas de que os pais discriminam os gastos familiares com educação no Brasil, de acordo com o sexo do filho.

\section{Estratégia empírica}

\section{Base de dados e apresentação das variáveis}

A Pesquisa Nacional por Amostra de Domicílios (PNAD), produzida pelo IBGE, contém informações referentes às características demográficas e socioeconômicas da população, tais como migração, educação, rendimento, trabalho infantil e fecundidade. Desde 2004 a pesquisa é realizada em todas as regiões do Brasil, incluindo todas as áreas rurais. A PNAD regular era aplicada anualmente, sendo que a última ocorreu em 2015. ${ }^{3}$

Nesse trabalho foi empregada a PNAD 2015, que, segundo o IBGE, pesquisou 356.904 pessoas e 151.189 unidades domiciliares distribuídas pelo Brasil. 0 domicílio é definido, de acordo com o IBGE, como o local de moradia estruturalmente separado e independente, constituído por um ou mais cômodos. Esses domicílios são classificados como particulares ou coletivos, podendo ser urbanos ou rurais.

A PNAD foi utilizada por conter a informação individual da rede escolar de cada criança, que está correlacionada com a propensão a realizar gastos em educação por parte dos

\footnotetext{
2 Os modelos não unitários são os que não exigem uma única função de utilidade para todos os membros da família.

${ }^{3}$ A PNAD foi substituída pela chamada PNAD contínua, que acompanha os domicílios durante cinco trimestres consecutivos de uma perspectiva mensal. A pesquisa é realizada para indicadores restritos da força de trabalho, trimestralmente para indicadores mais abrangentes quanto à força de trabalho e anualmente para os demais indicadores. A PNAD contínua estava em vigor desde 2012, mas apenas em 2016 substituiu, completamente, a PNAD regular.
} 
pais. A última POF refere-se ao biênio 2008-09 e contém apenas os gastos educacionais ao nível de família e não ao nível da criança.

Alguns cortes foram realizados, visando manter um padrão homogêneo da amostra da PNAD de 2015. Foram mantidas na amostra todas as famílias compostas por mais de uma pessoa e nas quais há mais de um filho de até 18 anos. Para essas famílias foram analisados apenas as crianças e jovens que estavam matriculados nos ensinos infantil, fundamental ou médio, uma vez que a decisão de estar ou não na escola é uma escolha familiar anterior ao que o presente estudo pretende elucidar. A idade de 18 anos foi escolhida como o corte da amostra por representar os adolescentes que ainda estão no ensino fundamental (que vai até os 14 ou 15 anos dependendo da duração do ensino) e que possam ter repetido alguma série. Por fim, foram analisadas apenas as pessoas declaradas como filhas e que vivem no domicílio.

Curi e Menezes-Filho (2010) dividiram os anos de ensino em três estágios: ensino fundamental I, que vai da $1^{\underline{a}}$ à $4^{\underline{a}}$ série; ensino fundamental II, da $5^{\underline{a}}$ à $8^{\underline{a}}$ série; e o ensino médio, que compreende os três anos finais do ensino básico. No presente trabalho foram utilizadas as séries de acordo com a PNAD (infantil, fundamental e médio), separando o

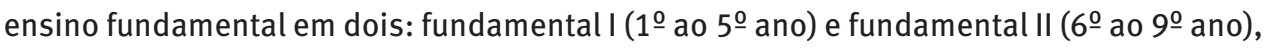
semelhante a Curi e Menezes-Filho (2010).

Com essa base de dados, a amostra final corresponde a 7.871 crianças que vivem em arranjos monoparentais femininos, representando $14,88 \%$ do total da amostra, 993 crianças que estão em famílias monoparentais masculinas (1,88\% do total) e 43.984 crianças que residem com ambos os pais (arranjo casal), respondendo por 83,23\% do total da amostra. 0 número de dormitórios e de banheiros é utilizado como características do domicílio. Outros fatores relacionados ao poder aquisitivo familiar são mensurados por meio da posse de telefone celular, TV por assinatura, acesso à internet, carro e máquina de lavar. A partir dessas variáveis criou-se uma nova variável denominada nível socioeconômico, que foi elaborada por meio de análise fatorial com a extração da componente principal. ${ }^{4}$ As características domiciliares são usadas como proxies secundárias da renda, uma vez que representam uma parcela residual e seriam complementares na mensuração do poder aquisitivo familiar.

Também são analisadas as características familiares. Segundo o IBGE, a família é o conjunto de pessoas ligadas por laços de parentesco, dependência doméstica ou normas de convivência, que residem na mesma unidade domiciliar e também a pessoa que mora só. A condição na família classifica as pessoas dentro de cada unidade familiar em função da pessoa de referência (responsável pela família) ou do seu cônjuge.

A decisão em matricular o filho na escola pública ou privada depende de diversos fatores, como o sexo da criança, a renda familiar, o arranjo familiar, entre outros. Portanto, foram utilizadas as variáveis constantes na Tabela 1, que também apresenta as estatísticas descritivas.

\footnotetext{
4 Os resultados da análise fatorial estão no Anexo, tanto a estatística de Kaiser-Meyer-Olkin (KMO) quanto o uniqueness, que representa o que cada variável explica na variância da nova variável.
} 
TABELA 1

Estatísticas descritivas - Características individuais, familiares, escolares e geográficas que afetam a decisão de matricular em escolas privadas, por tipo de arranjo familiar

\begin{tabular}{|c|c|c|c|c|}
\hline \multirow[t]{2}{*}{ Variáveis } & \multirow{2}{*}{ Descrição } & Casal & $\begin{array}{c}\text { Monoparental } \\
\text { masculino }\end{array}$ & $\begin{array}{c}\text { Monoparental } \\
\text { feminino }\end{array}$ \\
\hline & & $\begin{array}{c}\text { Média } \\
\text { (Desvio padrão) }\end{array}$ & $\begin{array}{c}\text { Média } \\
\text { (Desvio padrão) }\end{array}$ & $\begin{array}{l}\text { Média (Desvio } \\
\text { padrão) }\end{array}$ \\
\hline Educação privada & $\begin{array}{l}\text { Criança estuda na rede } \\
\text { privada }=1 \text {, caso contrário }=0\end{array}$ & $\begin{array}{r}0,205 \\
(0,404) \\
\end{array}$ & $\begin{array}{r}0,130 \\
(0,337) \\
\end{array}$ & $\begin{array}{r}0,138 \\
(0,345) \\
\end{array}$ \\
\hline Total de filhos & Total de filhos no domicílio & $\begin{array}{r}2,334 \\
(1,199) \\
\end{array}$ & $\begin{array}{r}2,000 \\
(1,145) \\
\end{array}$ & $\begin{array}{r}2,392 \\
(1,247) \\
\end{array}$ \\
\hline $\begin{array}{l}\text { Escolaridade do } \\
\text { responsável }\end{array}$ & $\begin{array}{l}\text { Escolaridade do responsável } \\
\text { (em anos) }\end{array}$ & $\begin{array}{r}8,487 \\
(4,250) \\
\end{array}$ & $\begin{array}{r}7,559 \\
(4,417) \\
\end{array}$ & $\begin{array}{r}8,715 \\
(4,074) \\
\end{array}$ \\
\hline $\begin{array}{l}\text { Idade do } \\
\text { responsável }\end{array}$ & $\begin{array}{l}\text { Idade do responsável } \\
\text { (em anos) }\end{array}$ & $\begin{array}{l}40,037 \\
(8,551)\end{array}$ & $\begin{array}{l}45,345 \\
(9,245)\end{array}$ & $\begin{array}{l}39,182 \\
(7,984)\end{array}$ \\
\hline Parente domicílio & Parentes moram no domicílio & $\begin{array}{r}0,095 \\
(0,293) \\
\end{array}$ & $\begin{array}{r}0,179 \\
(0,384) \\
\end{array}$ & $\begin{array}{r}0,195 \\
(0,396) \\
\end{array}$ \\
\hline Urbano & $\begin{array}{l}\text { Domicílio se localiza na área } \\
\text { urbana }=1 \text {, caso contrário =0 }\end{array}$ & $\begin{array}{r}0,844 \\
(0,363) \\
\end{array}$ & $\begin{array}{r}0,863 \\
(0,350) \\
\end{array}$ & $\begin{array}{r}0,931 \\
(0,254) \\
\end{array}$ \\
\hline Metropolitana & $\begin{array}{l}\text { Domicílio se localiza em região } \\
\text { metropolitana }=1 \text {, caso } \\
\text { contrário }=0\end{array}$ & $\begin{array}{r}0,300 \\
(0,458)\end{array}$ & $\begin{array}{r}0,331 \\
(0,471)\end{array}$ & $\begin{array}{r}0,372 \\
(0,483)\end{array}$ \\
\hline Ln renda per capita & $\begin{array}{l}\text { Logaritmo natural da renda } \\
\text { per capita }\end{array}$ & $\begin{array}{r}6,488 \\
(2,737) \\
\end{array}$ & $\begin{array}{r}6,541 \\
(2,662) \\
\end{array}$ & $\begin{array}{r}5,959 \\
(2,422) \\
\end{array}$ \\
\hline Banheiros domicílio & $\begin{array}{l}\text { Número de banheiros no } \\
\text { domicílio }\end{array}$ & $\begin{array}{r}1,377 \\
(0,741) \\
\end{array}$ & $\begin{array}{r}1,262 \\
(0,692) \\
\end{array}$ & $\begin{array}{r}1,209 \\
(0,543) \\
\end{array}$ \\
\hline Número dormitórios & $\begin{array}{l}\text { Número de dormitórios no } \\
\text { domicílio }\end{array}$ & $\begin{array}{r}2,282 \\
(0,685) \\
\end{array}$ & $\begin{array}{r}2,110 \\
(0,692) \\
\end{array}$ & $\begin{array}{r}2,039 \\
(0,730)\end{array}$ \\
\hline $\begin{array}{l}\text { Nível } \\
\text { socioeconômico }\end{array}$ & $\begin{array}{l}\text { Mede o nível socioeconômico } \\
\text { familiar. Foi elaborada por análise } \\
\text { fatorial por meio das variáveis } \\
\text { presentes na Tabela do Anexo }\end{array}$ & $\begin{array}{r}0,057 \\
(1,001)\end{array}$ & $\begin{array}{l}-0,190 \\
(1,023)\end{array}$ & $\begin{array}{l}-0,296 \\
(0,893)\end{array}$ \\
\hline Masculino & $\begin{array}{l}\text { Criança é do sexo masculino =1, } \\
\text { caso contrário =0 }\end{array}$ & $\begin{array}{r}0,511 \\
(0,500) \\
\end{array}$ & $\begin{array}{r}0,567 \\
(0,496) \\
\end{array}$ & $\begin{array}{r}0,499 \\
(0,491) \\
\end{array}$ \\
\hline Filho mais velho (1) & $\begin{array}{l}\text { Criança é o filho mais velho = } 1 \text {, } \\
\text { caso contrário }=0\end{array}$ & $\begin{array}{r}0,520 \\
(0,500) \\
\end{array}$ & $\begin{array}{r}0,575 \\
(0,495) \\
\end{array}$ & $\begin{array}{r}0,454 \\
(0,498) \\
\end{array}$ \\
\hline Segundo filho & $\begin{array}{l}\text { Criança é o segundo filho =1, } \\
\text { caso contrário = } 0\end{array}$ & $\begin{array}{l}0,327 \\
(0,69) \\
\end{array}$ & $\begin{array}{r}0,299 \\
(0,458) \\
\end{array}$ & $\begin{array}{r}0,343 \\
(0,475) \\
\end{array}$ \\
\hline Estuda na idade & $\begin{array}{l}\text { Criança estuda na idade certa: } \\
\text { a distorção idade-série é inferior } \\
\text { a } 2 \text { anos }=1 \text {, caso contrário }=0\end{array}$ & $\begin{array}{r}0,584 \\
(0,493)\end{array}$ & $\begin{array}{r}0,543 \\
(0,498)\end{array}$ & $\begin{array}{r}0,563 \\
(0,496)\end{array}$ \\
\hline Branco & $\begin{array}{l}\text { Criança é declarada branca/ } \\
\text { amarela }=1 \text {, caso contrário }=0\end{array}$ & $\begin{array}{r}0,466 \\
(0,499) \\
\end{array}$ & $\begin{array}{r}0,440 \\
(0,497) \\
\end{array}$ & $\begin{array}{r}0,407 \\
(0,491) \\
\end{array}$ \\
\hline Idade & Idade do estudante (em anos) & $\begin{array}{l}10,307 \\
(4,411) \\
\end{array}$ & $\begin{array}{l}12,64 \\
(3,77) \\
\end{array}$ & $\begin{array}{r}11,42 \\
(4,29) \\
\end{array}$ \\
\hline Ensino fundamental & $\begin{array}{l}\text { Criança estuda no ensino } \\
\text { fundamental }=1 \text {, caso } \\
\text { contrário }=0\end{array}$ & $\begin{array}{r}0,641 \\
(0,479)\end{array}$ & $\begin{array}{r}0,674 \\
(0,468)\end{array}$ & $\begin{array}{r}0,648 \\
(0,478)\end{array}$ \\
\hline Ensino médio & $\begin{array}{l}\text { Criança estuda no ensino } \\
\text { médio }=1 \text {, caso contrário = } 0\end{array}$ & $\begin{array}{r}0,170 \\
(0,376) \\
\end{array}$ & $\begin{array}{r}0,262 \\
(0,440) \\
\end{array}$ & $\begin{array}{r}0,227 \\
(0,419) \\
\end{array}$ \\
\hline Creche & $\begin{array}{l}\text { Criança frequenta a creche }=1 \text {, } \\
\text { caso contrário }=0\end{array}$ & $\begin{array}{r}0,090 \\
(0,287) \\
\end{array}$ & $\begin{array}{r}0,023 \\
(0,148) \\
\end{array}$ & $\begin{array}{r}0,061 \\
(0,240) \\
\end{array}$ \\
\hline $\begin{array}{l}\text { Classe de } \\
\text { alfabetização }\end{array}$ & $\begin{array}{l}\text { Criança estuda em CA = } 1 \text {, } \\
\text { caso contrário =0 }\end{array}$ & $\begin{array}{r}0,009 \\
(0,093) \\
\end{array}$ & $\begin{array}{r}0,006 \\
(0,077) \\
\end{array}$ & $\begin{array}{r}0,009 \\
(0,094) \\
\end{array}$ \\
\hline $\begin{array}{l}\text { Maternal, jardim de } \\
\text { infância, etc. }\end{array}$ & $\begin{array}{l}\text { Criança estuda no maternal = } 1, \\
\text { caso contrário = } 0\end{array}$ & $\begin{array}{r}0,089 \\
(0,284) \\
\end{array}$ & $\begin{array}{r}0,035 \\
(0,183) \\
\end{array}$ & $\begin{array}{r}0,054 \\
(0,227) \\
\end{array}$ \\
\hline Observações & Número de observações & 43.984 & 993 & 7.871 \\
\hline População & $\begin{array}{l}\text { População estimada por pesos } \\
\text { amostrais }\end{array}$ & 25.328 .183 & 535.138 & 4.389 .747 \\
\hline
\end{tabular}


A partir da Tabela 1 é possível observar que os arranjos familiares apresentam características diferentes para as variáveis analisadas. Salienta-se que as médias das variáveis binárias referem-se à proporção de pessoas que responderam 1. Assim, por exemplo, a proporção de filhos que estudam na rede privada é maior para os casais (20,5\%). Além disso, identificou-se que o número de dormitórios e de banheiros e o índice correspondente ao nível socioeconômico se mostram mais elevados quando a criança vive com ambos os pais.

No arranjo monoparental feminino, se comparado com o masculino, destaca-se uma maior proporção de crianças que estudam em escola privada. Segundo Phipps e Burton (1998), as despesas com as crianças só aumentam quando a renda da mulher aumenta, pois a elevação na renda masculina não está correlacionada com acréscimos nos cuidados com o filho. Sendo assim, esse pode ser um indicativo de que temos mais mulheres chefes de família investindo na educação das crianças em comparação aos seus pares chefes de família masculinos. Montali (2013) e Sorj (2004) ressaltam que a matrícula na educação infantil está positivamente correlacionada com a situação socioeconômica familiar. Dessa forma, a não consecução da vaga nesse nível de ensino dificultaria o acesso da mulher com filhos e sem cônjuge ao mercado de trabalho.

Outrossim, identifica-se que o arranjo monoparental feminino é aquele com o menor número de banheiros nos domicílios, bem como o menor número de cômodos na casa, além de um menor indicador de nível socioeconômico. Esse poderia ser um indício de uma condição financeira inferior, uma vez que tais variáveis são proxies de renda. As diferenças salariais entre homens e mulheres no mercado de trabalho brasileiro são apontadas na literatura (LOUREIRO et al., 2011; GIUBERTI; MENEZES-FILHO, 2005), indicando que a discriminação salarial pode explicar parte do diferencial de renda entre homens e mulheres, tornando-as financeiramente mais frágeis. Isso pode ser justificado, segundo Castro (2001, p. 42), por meio do fato de as mulheres chefes de famílias monoparentais, que passaram por processo de separação, terem oportunidades mais restritas para o investimento em suas carreiras em comparação aos seus pares sem cônjuge.

No entanto, a monoparentalidade feminina não pode ser sempre associada à pobreza, uma vez que, de acordo com Oliveira, Miranda-Ribeiro e Longo (2012), as mulheres de maior renda e escolaridade podem manter a chefia do lar por autonomia pessoal, ou após um processo de separação. Rivas, Jociles e Moncó (2011) apontam que a monoparentalidade feminina pode ser processo de escolha das mulheres que têm uma percepção própria de empoderamento e autonomia.

Outra possibilidade, no entanto, é da monoparentalidade ser advinda de gravidezes durante a adolescência, que, conforme Martinez et al. (2011), está associada diretamente a contextos socioeconômicos mais pobres. A renda mais baixa, entretanto, pode não ser fruto apenas da monoparentalidade, mas também da situação social em que a mulher se encontrava antes do nascimento da criança.

0 arranjo monoparental masculino possui características distintas das observadas no monoparental feminino. A formação do primeiro arranjo pode advir de aspectos alheios à 
escolha dos pais, como morte da progenitora ou dissolução do casamento, como ressalta Sousa (2008). Pinheiro et al. (2009) observaram que, embora lentamente, existiriam evidências de que os homens chefes de família (arranjo monoparental masculino) estariam assumindo tarefas que estejam além do provimento financeiro do lar, passando a assumir, portanto, papéis de cuidados com os filhos que deixam de ser exclusivamente da mulher.

Quanto à família da criança, é possível notar que a escolaridade (em anos) do responsável no arranjo monoparental feminino supera a dos demais tipos. 0 menor valor é encontrado no arranjo monoparental masculino. De acordo com Castro e Vaz (2007), quanto maior a escolaridade dos pais, mais elevado tende a ser o volume de recursos destinado à educação. Entretanto, como o número total de filhos, segundo a Tabela 1, é maior nos lares monoparentais femininos, espera-se que os recursos por filho sejam menores nesses arranjos.

Garcia et al. (2004) verificaram que as famílias monoparentais femininas com filhos são maiores, em questão de dimensionamento, quando comparadas às monoparentais masculinas, refletindo, consequentemente, um maior número de dependentes. Ainda segundo Garcia et al. (2004), a situação de famílias monoparentais femininas e com filhos se mostra a mais vulnerável de todas as tipologias, devido a um número mais elevado de dependentes e uma menor renda per capita domiciliar.

Verifica-se que as crianças em arranjos monoparentais masculinos têm maior distorção idade-série, além de possuírem idade média mais elevada em comparação com a situação dos seus pares nos demais arranjos. De acordo com Astone e Mclanaham (1991), crianças com pais separados apresentam aspirações educacionais mais baixas por parte dos pais, assim como um menor envolvimento dos pais nas tarefas escolares se comparadas com crianças que moram com pais que estão casados. Além disso, os autores observaram que os filhos de pais separados ficam desestimulados a completarem o ensino médio quanto maior for a incidência de pobreza nas famílias não intactas, ou seja, aquelas que já passaram por divórcios ou separações.

Algumas covariadas foram adicionadas, como dummies de unidades federativas (UFs) e de tamanho da população. Os efeitos fixos de UFs retiram os efeitos de oferta escolar em cada estado (ou Distrito Federal) do Brasil, incluindo efeitos de quantidade e qualidade da oferta escolar, evitando, com isso, uma análise enviesada ao se compararem arranjos em UFs distintas. Uma vez que a PNAD não apresenta o município em que o domicílio está localizado, o tamanho da população municipal é uma proxy para tamanho da oferta educacional por municípios.

\section{Metodologia}

Ao tomar a decisão de matricular os filhos na escola, os pais precisam escolher qual das redes de ensino a criança irá frequentar. Essa escolha é considerada binária, uma vez que é necessário escolher entre duas opções, ou seja, rede pública ou privada.

Os principais modelos binários são o logit e o probit. Os modelos se diferenciam pelo tipo de distribuição utilizada. Enquanto o logit usa a distribuição logística, o probit utiliza 
a normal. Portanto, foi estimado um modelo de escolha em que a variável dependente é binária e indica se o indivíduo frequenta ou não a rede de ensino privada:

$\operatorname{Pr}\left(Y_{\text {rede de ensino }}=1 \mid \chi\right)=G\left(\beta_{0}+\beta_{1} x_{1}+\beta_{2} x_{2}+\ldots+\beta_{k} x_{k}\right)=G\left(\beta_{0}+\chi \beta\right)$

Em que $\mathrm{G}$ é uma função de distribuição acumulada:

$G(z)=\frac{\exp (z)}{1+\exp (z)}=\Lambda(z)$

sendo $0<G(z)<1$ para qualquer valor de $z$.

0 modelo de escolha utilizado foi o logit, em que $G$, de acordo com Wooldridge (2006), é uma função logística, conforme a equação:

$G(z)=\operatorname{Pr}(y=1 \mid x)=G(x \beta)$

que está entre zero e um para todos os números $z$ reais. Essa é a função de distribuição cumulativa de uma variável aleatória logística padrão. Esse modelo pode ser derivado de um modelo de variável latente subjacente:

$y_{i}^{\star}=\beta_{1}+\beta_{2} X_{2 i}+\beta_{3} X_{3 i}+\cdots+\beta_{k} X_{k i}+\mu_{i}=X_{i} \beta+\mu_{i}$

Segundo Cameron e Trivedi (2009), o formato de um modelo binário básico com variável dependente é definido por:

$Y=\left\{\begin{array}{l}1 \text { com probabilidade } p \\ 0 \text { com probabilidade } 1-p\end{array}\right.$

sendo que a função de probabilidade para o resultado y é dada por $p y(1-p)^{(1-p)}$, com $E(y)=p$ e $\operatorname{Var}(y)=p(1-p)$.

0 modelo de regressão é formado ao parametrizar $p$ tal que $p$ dependa de uma função, com $x$ sendo um vetor de regressores $K$ x 1 e $\beta$ é um vetor de parâmetros desconhecidos. Assim, a probabilidade condicional é definida por:

$p_{i}=\operatorname{Pr}\left(y_{i}=1 / x\right)=F\left(x^{\prime} \beta\right)$

Em um modelo logit, $F()=.\Lambda$ (.), a função de probabilidade condicional é definida por: $p_{i}=\operatorname{Pr}\left(y_{i}=1 / x\right)=\Lambda()=.\frac{e^{\left(x^{\prime} \beta\right)}}{1+e^{\left(x^{\prime} \beta\right)}}$

A estimação do modelo logit ocorre por máxima verossimilhança. Para uma amostra de $N$ observações independentes, o estimador de máxima verossimilhança maximiza a função associada ao log-verossimilhança:

$Q(\beta)=\sum_{i=1}^{\mathrm{n}}\left[y_{i} \ln F\left(x^{\prime} \beta\right)+(1-\mathrm{y}) \ln \left\{1-F\left(x^{\prime} \beta\right)\right\}\right]$

No presente trabalho pretende-se estimar a probabilidade de a criança entre zero e 18 anos estudar em uma escola pública ou privada condicionada pelas características que afetam essa tomada de decisão. Assim, a variável dependente é uma variável binária que representa a rede de ensino que a criança frequenta, podendo ser descrita como: 


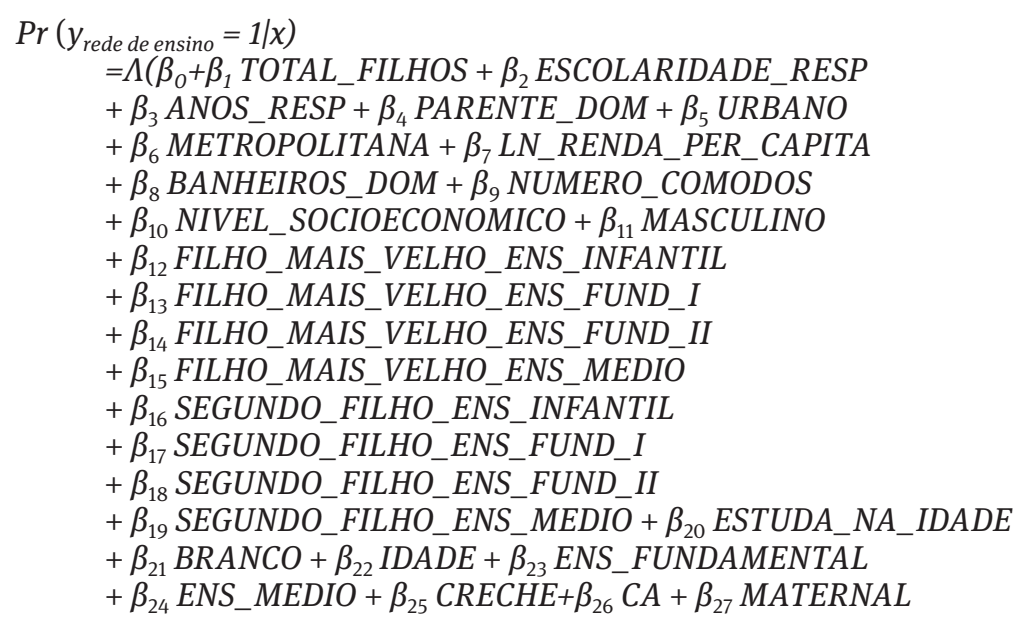

As variáveis TOTAL_FILHOS, ESCOLARIDADE_RESP, ANOS_RESP, PARENTE_DOM, LN_ RENDA_PER_CAPITA e NIVEL_SOCIOECONOMICO são vetores de característica da família. Já as variáveis URBANO, METROPOLITANA, BANHEIROS_DOM, NUMERO_DORMITORIOS são vetores de característica do domicílio. Por fim, as variáveis MASCULINO, FILHO_MAIS_VELHO, SEGUNDO_FILHO, ESTUDA_NA_IDADE, BRANCO, ENS_MEDIO, CRECHE, CA e MATERNAL são vetores de característica da criança.

As características inseridas no modelo logit foram definidas com base nos estudos de Curi e Menezes-Filho (2010) e Freitas (2015). 0 processo de estimação ocorreu por meio da regressão do modelo logit para a amostra toda - coluna total da Tabela 2 - e, posteriormente, para cada arranjo familiar.

\section{Resultados e discussão}

De acordo com os resultados do modelo, pode-se observar como as características dos indivíduos e dos arranjos familiares estão associadas à decisão familiar de matricular os filhos na rede pública ou privada. Os resultados estão descritos em (odds ratio, OR), ou seja, qual é a razão de chances de ocorrência da variável dependente se alterar com a variação de uma unidade na variável independente. Os resultados podem variar de zero a mais infinito, sendo que abaixo de 1 significa uma razão de chance negativa e acima, positiva. As estimações foram realizadas segundo o tipo de arranjo parental e as Tabelas 2, 3 e 4 são apresentadas segundo as características da criança, da família e do domicílio, respectivamente. Salienta-se, porém, que as três tabelas referem-se às mesmas estimações, apenas separamos os resultados para uma melhor visualização. A Tabela 2 traz o resultado das estimações, segundo as características da criança (cor, ordem de nascimento, idade e nível de ensino). 
Rizzotto, J.S. et al. Os arranjos familiares importam no momento de decidir em qual rede de ensino matricular...

TABELA 2

Resultados das variáveis da criança na regressão do modelo logit, por tipo de arranjo familiar

\begin{tabular}{|c|c|c|c|c|}
\hline Variáveis & Total & Casal & $\begin{array}{c}\text { Monoparental } \\
\text { masculino }\end{array}$ & $\begin{array}{l}\text { Monoparental } \\
\text { feminino }\end{array}$ \\
\hline \multirow[t]{2}{*}{ Estuda na idade correta } & $1,936^{\star \star \star}$ & $2,043^{\star \star \star}$ & 0,589 & $1,877^{\star \star}$ \\
\hline & $(0,230)$ & $(0,276)$ & $(0,406)$ & $(0,488)$ \\
\hline \multirow[t]{2}{*}{ Masculino } & $0,939 * \star$ & 0,955 & 0,655 & $0,852^{\star}$ \\
\hline & $(0,0296)$ & $(0,0325)$ & $(0,196)$ & $(0,0760)$ \\
\hline \multirow[t]{2}{*}{ Filho mais velho (1), ensino infantil } & $1,269^{\star \star}$ & $1,292^{\star \star}$ & 0,089 & 1,514 \\
\hline & $(0,188)$ & $(0,163)$ & $(0,184)$ & $(0,549)$ \\
\hline \multirow[t]{2}{*}{ Filho mais velho (1), fundamental I } & $1,913^{\star \star \star}$ & $1,894^{\star \star \star}$ & 4,829 & $1,989 * \star$ \\
\hline & $(0,188)$ & $(0,202)$ & $(5,036)$ & $(0,545)$ \\
\hline \multirow[t]{2}{*}{ Filho mais velho (1), fundamental II } & $2,329^{\star \star \star}$ & $2,356^{\star \star \star}$ & 2,526 & $2,096^{\star \star \star}$ \\
\hline & $(0,244)$ & $(0,270)$ & $(2,493)$ & $(0,595)$ \\
\hline \multirow[t]{2}{*}{ Filho mais velho (1), ensino médio } & $1,660^{\star \star}$ & $1,587^{\star \star}$ & $0,140^{\star}$ & 2,324 \\
\hline & $(0,352)$ & $(0,373)$ & $(0,165)$ & $(1,285)$ \\
\hline \multirow[t]{2}{*}{ Segundo filho, ensino infantil } & 0,934 & 1,245 & 0,023 & 0,791 \\
\hline & $(0,106)$ & $(0,127)$ & $(0,565)$ & $(0,272)$ \\
\hline \multirow[t]{2}{*}{ Segundo filho, fundamental I } & $1,239 * \star$ & $1,245^{\star \star}$ & 0,824 & 1,304 \\
\hline & $(0,115)$ & $(0,127)$ & $(0,826)$ & $(0,315)$ \\
\hline \multirow[t]{2}{*}{ Segundo filho, fundamental II } & $1,572^{\star \star \star}$ & $1,583^{\star \star \star}$ & 0,619 & $1,626^{\star}$ \\
\hline & $(0,162)$ & $(0,180)$ & $(0,708)$ & $(0,435)$ \\
\hline \multirow[t]{2}{*}{ Segundo filho, ensino médio } & 1,400 & 1,415 & 0,176 & 1,524 \\
\hline & $(0,302)$ & $(0,339)$ & $(0,206)$ & $(0,847)$ \\
\hline \multirow[t]{2}{*}{ Branco } & $1,654^{\star \star \star}$ & $1,674^{\star \star \star}$ & $2,803^{\star \star \star}$ & $1,526^{\star \star \star}$ \\
\hline & $(0,0578)$ & $(0,0634)$ & $(0,947)$ & $(0,150)$ \\
\hline \multirow[t]{2}{*}{ Idade } & $0,847^{\star \star \star}$ & $0,845^{\star \star \star}$ & 0,862 & $0,866^{\star \star \star}$ \\
\hline & $(0,00969)$ & $(0,0105)$ & $(0,0870)$ & $(0,0267)$ \\
\hline \multirow[t]{2}{*}{ Ensino médio } & $2,333^{\star \star \star}$ & $2,680^{\star \star \star}$ & 4,833 & 1,317 \\
\hline & $(0,565)$ & $(0,723)$ & $(6,368)$ & $(0,807)$ \\
\hline \multirow[t]{2}{*}{ Creche } & $2,160^{\star \star \star}$ & $2,115^{\star \star \star}$ & 26,05 & $2,980^{\star \star}$ \\
\hline & $(0,433)$ & $(0,468)$ & $(64,67)$ & $(1,517)$ \\
\hline \multirow[t]{2}{*}{ Classe de alfabetização (CA) } & $2,522^{\star \star \star}$ & $2,547^{\star \star \star}$ & $83,56^{\star}$ & 2,372 \\
\hline & $(0,560)$ & $(0,623)$ & $(206,0)$ & $(1,429)$ \\
\hline \multirow[t]{2}{*}{ Maternal, jardim de infância } & $3,105^{\star \star \star}$ & $3,135^{\star \star \star}$ & $177,1^{\star \star}$ & $3,188^{\star \star}$ \\
\hline & $(0,583)$ & $(0,649)$ & $(467,7)$ & $(1,568)$ \\
\hline
\end{tabular}

Fonte: IBGE. Pesquisa Nacional por Amostra de Domicílios - PNAD 2015. Elaboração dos autores.

(1) Filho mais velho no domicílio.

Nota: ${ }^{\star \star \star} p<0,01,{ }^{\star \star} p<0,05,{ }^{\star} p<0,10$.

Erros robustos entre parênteses.

Ao observar os arranjos familiares, é possível identificar que os filhos que estudam na idade correta tendem a ter chances maiores de frequentar uma escola privada. Logo, a distorção idade-série faz com que as crianças tenham maior probabilidade de irem para o ensino público. Essa relação pode ter fundamento por meio da teoria de Becker (1993), na qual as famílias investem na criança até o ponto em que o retorno marginal do investimento se iguale ao custo marginal do mesmo. Consequentemente, uma vez que a criança não tenha um bom desempenho escolar, acarretando a reprovação da 
mesma, os pais terão seu retorno esperado reduzido. Sendo assim, as chances de interromperem o investimento educacional no filho (arcando com as despesas de uma escola privada) aumentam. 0 tempo adicional vivenciado na escola incorrerá em maior custo familiar, já que aumenta o tempo fora do mercado de trabalho (BECKER, 1993).

Albernaz et al. (2002), Ferrão et al. (2001), Palermo et al. (2014), entre outros, mostram que a distorção idade-série está negativamente correlacionada com o desempenho estudantil. Portella et al. (2017) evidenciam, por meio dos dados da PNAD de 2013, que $46 \%$ dos alunos matriculados em escolas públicas apresentam alguma distorção idade-série. Ademais, as escolas públicas registram menor desempenho do que as privadas, mesmo após controlar por aspectos relacionados ao nível socioeconômico e à distorção idade-série (ALBERNAZ et al., 2002; FRANÇA; GONÇALVES, 2008).

0 investimento em educação privada se difere segundo o sexo da criança e do responsável pelo domicílio. As filhas são beneficiadas no domicílio monoparental feminino, ao contrário do resultado do estudo de Emerson e Souza (2002), que apontou para um benefício aos meninos, sem discriminação de arranjo familiar. Entretanto, Thomas (1994) observou que, no Brasil, as mães beneficiam as filhas, e os pais, os filhos. Os resultados encontrados estão em consonância, em parte, com Thomas (1994), uma vez que ser menino, em um arranjo monoparental feminino, diminui as chances de estudar na rede privada. Porém, não há efeitos significativos para os arranjos monoparentais masculinos ou biparentais. O resultado contrasta com o de Loyd e Blanc (1996), pois os autores evidenciaram, para algumas cidades africanas, que, apesar de mais pobres, as mulheres investem mais recursos, tempo e apoio emocional para a educação do filho.

0 investimento das mães nas filhas pode representar um comportamento altruísta das mulheres. Uma das possíveis razões para a discriminação do investimento segundo o sexo do filho é poder proporcionar à filha condições educacionais superiores que poderão auxiliá-la na obtenção de melhores posições (estudantis ou profissionais). Ademais, a mãe, por meio da educação, pode estar fazendo uma tentativa de empoderamento da filha, para que a mesma não sofra discriminações futuras por causa do gênero.

Conforme Glomm (1997), as crianças de famílias pobres têm um elevado custo de oportunidade para permanecer estudando, uma vez que precisam trabalhar para ajudar no sustento familiar, diferentemente daquelas com poderes aquisitivos maiores. Menezes-Filho e Pazello (2004) afirmam que, apesar de o acesso ao primeiro ano escolar ser quase universal, crianças de famílias mais pobres tendem a abandonar o estudo antes da sua conclusão. Uma das razões para essa desistência, segundo os autores, seria a qualidade educacional média inferior que seria recebida no sistema público.

Quanto às características do filho, as crianças que se autodeclararam brancas possuem uma probabilidade maior de estudar na escola privada em todos os arranjos familiares, sendo estatisticamente significantes a $1 \%$. No que diz respeito às variáveis de filho mais velho e segundo filho, é possível observar que o filho mais velho que estuda no ensino fundamental I ou no ensino fundamental II tem maiores chances de estudar 
na rede privada em todos os arranjos parentais, exceto no monoparental masculino. No ensino médio, os filhos de arranjos biparentais têm maior probabilidade de estudarem em escola privada e os filhos de arranjos monoparentais chefiados por homens, menor.

As variáveis de segundo filho só são significativas no ensino fundamental I e II, em alguns arranjos familiares. Se estiver no ensino fundamental I, o segundo filho tende a ter mais chances de estudar na rede privada no arranjo biparental. Já no ensino fundamental II, o único arranjo que não tem significância são as famílias monoparentais masculinas. A variável segundo filho no ensino médio não apresentou significância em nenhum dos arranjos. De acordo com Ejrner e Portner (2004), existe a possibilidade de a criança mais velha ingressar no mercado de trabalho mais cedo e, com isso, aumentar os recursos disponíveis para a criança mais nova. Sendo assim, o filho mais novo seria beneficiado por meio da entrada do irmão mais velho no mercado de trabalho.

Em relação ao curso que frequenta, é possível observar que todos os níveis possuem impactos positivos na propensão de matricular a criança em escola privada, em relação ao ensino fundamental, excluindo-se creche para arranjos monoparentais masculinos e ensino médio para ambos arranjos monoparentais. Tal resultado pode demonstrar dois diferentes pontos: primeiro, que os pais têm maior propensão a investir em educação infantil porque a oferta de vagas é mais escassa na rede pública; segundo, a propensão a gastar com o ensino médio é maior do que com o ensino fundamental porque as famílias podem estar mais propensas a investir mais recursos para o acesso ao ensino superior. Freitas (2015) verificou que os filhos matriculados no ensino fundamental têm $21 \%$ mais chances de receber investimento em educação em relação aos demais filhos. Já aqueles que estão matriculados no ensino médio têm $41 \%$ a mais de chances de receber o investimento em educação em relação aos demais filhos do domicílio. 0 resultado encontrado por Freitas (2015) pode ser devido à maior oferta de vagas no ensino médio em escola pública e ao fato de a família decidir investir em outras fontes de recursos educacionais, como livros, cursos de inglês e cursinho pré-vestibular.

A variável idade é negativamente correlacionada com a propensão da família em matricular o filho em escola privada. Essa evidência contrapõe-se ao dado encontrado por Freitas (2015), que aponta que, para cada ano a mais da criança, a probabilidade de ter gastos com educação aumenta em 5,2\%.

Na Tabela 3 é apresentado o resultado das estimações, segundo as características familiares (idade e escolaridade do responsável, presença de parentes e o total de crianças no domicílio). Destaca-se que a coluna total da Tabela 3, que contém todos os tipos de famílias, não mostra diferenças estatisticamente significativas entre a decisão de matricular os filhos em escolas privadas para os casais, mas as famílias monoparentais masculinas têm menor probabilidade de matricular seus filhos em escola privada em relação ao grupo base (famílias monoparentais femininas). 
TABELA 3

Resultados das variáveis da família na regressão do modelo logit, por tipos de arranjo familiar

\begin{tabular}{|c|c|c|c|c|}
\hline Variáveis & Total & Casal & $\begin{array}{c}\text { Monoparental } \\
\text { masculino }\end{array}$ & $\begin{array}{l}\text { Monoparental } \\
\text { feminino }\end{array}$ \\
\hline \multirow[t]{2}{*}{ Casal } & 0,958 & & & \\
\hline & $(0,0473)$ & & & \\
\hline \multirow[t]{2}{*}{ Monoparental masculino } & $0,790^{\star}$ & & & \\
\hline & $(0,111)$ & & & \\
\hline \multirow[t]{2}{*}{ Escolaridade do responsável } & $1,223^{\star \star \star}$ & $1,223^{\star \star \star}$ & $1,235^{\star \star \star}$ & $1,213^{\star \star \star}$ \\
\hline & $(0,00700)$ & $(0,00750)$ & $(0,0584)$ & $(0,0214)$ \\
\hline \multirow[t]{2}{*}{ Idade do responsável } & $1,036^{\star \star \star}$ & $1,035^{\star \star \star}$ & $1,052^{\star \star \star}$ & $1,050^{\star \star \star}$ \\
\hline & $(0,00231)$ & $(0,00247)$ & $(0,0177)$ & $(0,00730)$ \\
\hline \multirow[t]{2}{*}{ Presença de parente no domicílio } & $0,814^{\star \star \star}$ & $0,808^{\star \star \star}$ & 0,930 & 0,880 \\
\hline & $(0,0460)$ & $(0,0528)$ & $(0,388)$ & $(0,105)$ \\
\hline \multirow[t]{2}{*}{ Total de filhos } & $0,654^{\star \star \star}$ & $0,658^{\star \star \star}$ & $0,618^{*}$ & $0,621^{\star \star \star}$ \\
\hline & $(0,0175)$ & $(0,0189)$ & $(0,162)$ & $(0,0516)$ \\
\hline
\end{tabular}

Fonte: IBGE. Pesquisa Nacional por Amostra de Domicílios - PNAD 2015. Elaboração dos autores.

Nota: ${ }^{* \star *} p<0,01,{ }^{* \star} p<0,05,{ }^{*} p<0,10$

Erros robustos entre parênteses.

Quanto às características dos pais, a escolaridade do responsável impacta positivamente em todos os arranjos, ou seja, quanto mais os pais estudam, maior é a propensão de colocar os seus filhos em escolas privadas. De acordo com Goldring e Phillips (2006), pais com maior nível educacional tendem a dar mais valor à educação dos filhos. Menezes e Pazello (2004) também verificaram que a parcela dos estudantes que frequentam a rede privada aumenta de acordo com o nível educacional dos pais. Ademais, outros estudos mostram que há uma relação positiva entre a educação dos pais e a probabilidade de matricularem seus filhos na escola privada (COLEMAN; HOFFER; KILGORE, 1982; NOELL, 1982; COLEMAN; HOFFER, 1987; LONG; TOMA, 1988; LANKFORD; WYCKOFF, 1992). A idade do responsável também tem um impacto positivo na escolaridade das crianças, sendo estatisticamente significante em todos os arranjos a $1 \%$. Segundo Ejrner e Portner (2004), mães e pais mais velhos podem decidir investir mais nos filhos, uma vez que a renda disponível é maior.

No entanto, ter parente morando no domicílio reduz as chances de o filho estudar em escola privada para o arranjo familiar casal. Essa correlação acontece porque, nas famílias biparentais, é possível que os parentes sejam economicamente dependentes e, assim, não contribuam com a renda per capita da casa, corroborando a correlação encontrada. Segundo Fontes (2014), o número médio de idosos que moram no domicílio é menor nos arranjos monoparentais se comparado aos biparentais. A população idosa, por meio da sua aposentadoria, pode contribuir ou não com a renda familiar. Dentro de um contexto em que a renda do idoso é complementar à renda familiar, o aumento nos recursos disponíveis para a família pode elevar as chances de matricular os filhos em escola privada. Entretanto, para aqueles domicílios em que a renda do idoso não se mostra suficiente no complemento da renda do lar, a presença da pessoa de idade reduz 
os recursos disponíveis na família. Fontes (2014) aponta que o envelhecimento faz com que as despesas aumentem porque os idosos são os usuários mais frequentes de serviços médicos mais complexos e internações mais prolongadas, diminuindo, portanto, as chances de matricular os filhos em escolas privadas.

Nos arranjos monoparentais, não foram encontradas estimativas estatisticamente significantes da presença de parentes sobre a chance de estudar em escola privada. Entretanto, de acordo com Fontes (2014), nos arranjos monoparentais, muitas vezes os parentes residem no domicílio para prover recursos, reduzindo os impactos das dificuldades cotidianas. Essa variável pode impactar no tamanho da família, que é um fator importante na participação na força de trabalho e na frequência escolar. Portanto, as famílias maiores tendem a precisar de renda extra para o sustento de todos, o que, consequentemente, impede o envio do filho para a escola porque é preciso mandá-lo para o mercado de trabalho (EMERSON; SOUZA, 2008).

0 total de filhos é outra variável que tem impacto negativo na educação privada das crianças. De acordo com as hipóteses de diluição de recursos e de rivalidade entre irmãos, os recursos destinados a cada filho diminuem com o aumento do número de crianças. Essa relação inversa ocorre pelo mesmo motivo da presença de parentes, pois, quanto mais filhos uma família possuir e precisar sustentar, menos renda disponível restará para a educação dos demais. Conforme Emerson e Souza (2008), as famílias também podem aumentar o número de filhos como uma resposta à pobreza, porque assim podem ampliar a renda familiar mandando alguns deles para o mercado de trabalho. Segundo Marteleto (2002), uma família com um menor número de filhos tende a dar mais oportunidade a cada criança de ter um nível educacional maior.

A Tabela 4 apresenta as variáveis ao nível de domicílio, como localização, tamanho do domicílio e variáveis de renda. Destaca-se que todas as variáveis têm significância de $1 \%$ em todas as equações estimadas.

Em relação às características do domicílio, se está localizado em área urbana, as chances de a criança frequentar uma escola privada são maiores, assim como na variável metropolitana. 0 resultado pode ser decorrente de uma maior oferta desse tipo de ensino nesse ambiente vis-à-vis aos demais. 0 número de banheiros no domicílio também impacta positivamente a chance de estudar em uma escola privada, uma vez que, quanto maior o número de banheiros no domicílio, maior tende a ser a sua renda. O mesmo ocorre com o número de dormitórios, para os arranjos biparentais. Taubman (1989) também encontrou relação positiva entre renda e investimento educacional, em que a educação da criança é um bem de investimento e, consequentemente, as famílias mais pobres possuem liquidez limitada, não podendo, portanto, investir em um nível considerado ótimo no capital humano dos seus filhos. 
TABELA 4

Resultados das variáveis do domicílio na regressão do modelo logit, por tipos de arranjo familiar

\begin{tabular}{|c|c|c|c|c|}
\hline Variáveis & Total & Casal & $\begin{array}{c}\text { Monoparental } \\
\text { masculino }\end{array}$ & $\begin{array}{c}\text { Monoparental } \\
\text { feminino }\end{array}$ \\
\hline \multirow[t]{2}{*}{ Urbano } & $3,150^{\star \star \star}$ & $3,243^{\star \star \star}$ & $2,637^{\star}$ & $2,098^{\star *}$ \\
\hline & $(0,289)$ & $(0,316)$ & $(1,420)$ & $(0,652)$ \\
\hline \multirow[t]{2}{*}{ Metropolitana } & $1,695^{\star \star \star}$ & $1,561^{\star \star \star}$ & $8,477^{\star \star}$ & $3,149^{\star \star \star}$ \\
\hline & $(0,138)$ & $(0,134)$ & $(7,699)$ & $(0,943)$ \\
\hline \multirow[t]{2}{*}{ Banheiros no domicílio } & $2,181^{\star \star \star}$ & $2,188^{\star \star \star}$ & $2,113^{\star \star}$ & $2,189^{\star \star \star}$ \\
\hline & $(0,0551)$ & $(0,0579)$ & $(0,757)$ & $(0,186)$ \\
\hline \multirow[t]{2}{*}{ Número de dormitórios } & $1,201^{\star \star \star}$ & $1,225^{\star \star \star}$ & 1,156 & 1,036 \\
\hline & $(0,0355)$ & $(0,0394)$ & $(0,372)$ & $(0,083)$ \\
\hline \multirow[t]{2}{*}{ Ln da renda per capita } & $1,061^{\star \star \star}$ & $1,066^{\star \star \star}$ & 0,987 & $1,029^{*}$ \\
\hline & $(0,00607)$ & $(0,00665)$ & $(0,0442)$ & $(0,016)$ \\
\hline \multirow[t]{2}{*}{ Nível socioeconômico } & $2,231^{\star \star \star}$ & $2,203^{\star \star \star}$ & $3,506^{\star \star \star}$ & $2,522^{\star \star \star}$ \\
\hline & $(0,0569)$ & $(0,0609)$ & $(0,744)$ & $(0,187)$ \\
\hline$N$ & 5.3047 & 43.984 & 889 & 7.871 \\
\hline Wald Chi² & 8048,43 & 6936,80 & 190,67 & 1063,79 \\
\hline P-Valor & 0,00 & 0,00 & 0,00 & 0,00 \\
\hline Pseudo R2 & 0,4012 & 0,4029 & 0,4799 & 0,3788 \\
\hline
\end{tabular}

Fonte: IBGE. Pesquisa Nacional por Amostra de Domicílios - PNAD 2015. Elaboração dos autores.

Nota: ${ }^{\star * \star} p<0.01,{ }^{* \star} p<0.05,{ }^{*} p<0.10$. Erros robustos entre parênteses.

Controlado por efeitos fixos de unidade federativa e pela projeção de população do município.

Os resultados que mostram que a maior renda está associada à maior chance de matricular os filhos em escola privada corroboram uma ampla literatura (GOLDRING; ROWLEY, 2008; BUTTIN; CORDES; KIRBY, 1998; JIMENEZ; LOCKHEED; PAQUEO, 1991). Esse resultado, no entanto, pode ser preocupante no sentido de que pode perpetuar diferenças educacionais ao longo das gerações. Segundo Ferreira (2001), a desigualdade educacional perpetua-se no longo prazo, pois os recursos direcionados pelo poder político não seriam suficientes para aumentar a qualidade da escola pública que é frequentada pelas pessoas de menor renda.

Além disso, conforme Ferreira (2001), a desigualdade educacional pode persistir na ausência de um mercado de crédito ao nível da educação básica que seja capaz de financiar uma educação de qualidade (no caso discutido pelo autor, privada) para aqueles que não têm condições, produzindo uma renda menor de geração em geração, ocasionando uma armadilha da pobreza. Para Glomm (1997), essa armadilha está associada a um maior desequilíbrio no poder político, que está correlacionado positivamente com a riqueza. 0 autor afirma haver um ciclo vicioso que é perpetuado para todas as gerações.

França e Gonçalves (2013) mostram que há um aumento no número de estudantes do ensino fundamental em escolas privadas. Segundo Sampaio e Guimarães (2009), o crescimento da renda nos últimos anos pode ter sido o grande propulsor da migração dos estudantes das escolas públicas para as privadas. De acordo com Ferreira (2001), as diferenças de qualidade entre o ensino público e o privado são tão grandes que, uma vez que o agente possa arcar com a educação privada, ele tomará a decisão por custear os estudos. 
Alves (2010) mostra que, de acordo com os resultados do Saeb (Sistema de Avaliação da Educação Básica) 2005 para o Rio de Janeiro, alunos de escolas privadas possuem resultados superiores aos de escolas municipais. A autora salienta que os melhores resultados apontados podem manter a estratificação educacional.

Não há, no entanto, uma certeza de que a matrícula dos filhos em escolas privadas seja a escolha pela melhor qualidade, uma vez que escolas públicas podem possuir qualidade educacional superior às privadas. Todavia, para alguns arranjos familiares, há uma maior disposição a pagar pela matrícula. Outro ponto que deve ser salientado é que, em muitos casos, o maior deslocamento até uma escola pública ou a ausência de oferta de vagas nessa rede - para o caso da educação infantil - pode obrigar os pais a gastos em escolas privadas.

\section{Considerações finais}

No presente trabalho foram analisados os determinantes da escolha da família quanto à rede de ensino segundo os tipos de arranjos familiares e a ordem de nascimento das crianças. Os arranjos familiares estão sofrendo mudanças no Brasil. Tanto as famílias monoparentais estão aumentando em proporção, quanto a chefia dos domicílios está se alterando, com ênfase para o crescimento das mulheres nesse papel. Como a família altera os investimentos na educação dos filhos de acordo com as suas preferências e restrições orçamentárias, os diferentes arranjos familiares podem ter incentivos diversos no momento de matricular a criança em uma escola privada. Os pais, ao pensarem em qual rede de ensino matricularão os filhos, podem analisar diferentes fatores, como a renda e a qualidade do ensino.

No Brasil, há uma grande diferença entre os ensinos público e privado. Sendo assim, os pais que possuem condições financeiras para arcar com os custos dos estudos dos seus filhos podem optar por pagar por um ensino privado em vez de matricular em um ensino gratuito. Cabe destacar que o estudo visa analisar as matrículas na rede privada não como uma defesa em função de tal rede de ensino ou um incentivo à mesma, mas sim como as escolhas parentais que levam à decisão de arcar com os custos da educação, embora supostamente exista oferta gratuita de ensino.

Neste estudo, foi realizada uma regressão com o modelo logit com as variáveis que afetam essa escolha. Os resultados mostram que a chance de estudar na rede privada diminui conforme os níveis de ensino aumentam. Ou seja, estar no ensino infantil faz com que se tenha mais chances de frequentar a rede privada. No Brasil, o número de creches públicas é pequeno. Em 2015, de acordo com o Censo Escolar da Educação Básica, divulgado pelo Instituto Nacional de Estudos e Pesquisas Educacionais (Inep), no Estado de São Paulo, havia 5.298 creches municipais, enquanto as escolas privadas somavam 7.617 , na área urbana. Ademais, nos Estados de Alagoas, Amapá, Bahia, Distrito Federal (estadual), Minas Gerais, Paraíba, Pernambuco, Rio de Janeiro, Rio Grande do Sul e Sergipe, o número de creches privadas é superior às municipais urbanas, com exceção do Distrito Federal, onde o número de creches estaduais se compara com as privadas. 
A redução no número de membros das famílias brasileiras, juntamente com os incentivos à entrada das mulheres no mercado de trabalho, coloca uma pressão sobre a demanda de vagas em creches. Porém, a escassez de opções ou vagas obriga os pais a arcarem com os custos da creche. A redução das chances de frequentar o ensino privado à medida que aumenta o nível de ensino pode ser acarretada pelo crescimento da oferta das escolas públicas nos ensinos fundamental e médio ou por causa da competição, em que duas crianças precisam competir pelos mesmos recursos e independe do arranjo familiar no qual o filho se encontra.

Observou-se que o sexo da criança afeta as chances de a mesma estudar na rede privada se ela estiver em um arranjo monoparental feminino. Nesse caso, a filha tem maiores chances de frequentar uma escola privada. Esse resultado apontaria para um comportamento altruísta da mulher, além de mostrar que essa preferência pode ser uma tentativa de empoderamento da menina para que ela não passe pelas mesmas dificuldades que a mãe.

Ademais, encontrou-se no estudo a importância da ordem de nascimento dos filhos, uma vez que esta afeta as chances de a criança estudar na rede privada. 0 filho mais velho e o segundo filho têm chances maiores de frequentar o ensino privado se comparados aos filhos nascidos posteriormente, independentemente do arranjo familiar.

0 nível de ensino que apresenta a maior chance de os pais matricularem na rede privada é o jardim de infância/maternal. As evidências suportam a implementação de políticas públicas voltadas para as creches públicas, a fim de poder dar oportunidade a todos. De acordo com Heckman (2000), investir na educação nos anos iniciais é fundamental para a vida da criança. Os investimentos no ensino infantil são os que trazem um maior retorno e, portanto, não existe política pública mais eficaz do que investir na educação das crianças nos primeiros anos de vida (BECKER; TOMES, 1979; HECKMAN, 2000).

Por meio deste estudo, foi possível verificar que o arranjo monoparental masculino é o que possui o comportamento mais diversificado se comparado com os demais. Esse arranjo merece uma investigação mais profunda, pois as evidências apontam que as preferências entre os sexos são distintas. Halpern (2004), por exemplo, menciona que os formuladores de política devem ter atenção para o estresse que os pais ou mães que trabalham sofrem, em especial os chamados "pais/mães solteiros(as)". Conforme o autor, somente após uma visão abrangente sobre as mudanças na família e impactos sobre os resultados e bem-estar é que as políticas públicas poderão ser bem-sucedidas.

No entanto, o trabalho possui três limitações. A primeira é que por meio da PNAD só é possível identificar a relação de parentesco com o chefe da família, logo não há como afirmar que o cônjuge é o pai da criança, ainda que o arranjo familiar seja identificado. No caso de o cônjuge ser do sexo feminino essa identificação é possível, uma vez que há a variável de número de filhos tidos pela mulher morando no domicílio. No entanto, para o homem que é o cônjuge essa verificação não se faz possível (BARROS et al., 2008). A segunda limitação é que as escolas privadas podem ter uma qualidade inferior às públicas, apesar de não ser o que ocorre na média. Sendo assim, famílias podem estar tendo um gasto com educação, mas o estabelecimento possui uma baixa qualidade de ensino. 
A limitação mais importante do estudo é o fato de não ser possível identificar os filhos que estão fora do domicílio, porque a PNAD não aborda essa questão. Pelas informações disponíveis, pode-se identificar quantos são os filhos de uma mulher que não vivem no domicílio, mas não as características deles. Em cerca de $28 \%$ dos domicílios da amostra, a mulher possui pelo menos um filho que não mora naquele domicílio. Há, no entanto, duas possibilidades de vieses para estes filhos: a primeira é que eles podem ser economicamente dependentes da mãe, reduzindo os investimentos nos filhos ainda no domicílio. Segundo, podem ajudar financeiramente suas mães, aumentando os investimentos nos filhos restantes dentro da residência. Caso não haja uma relação de dependência financeira, espera-se ausência de efeito sobre os gastos educacionais dos demais filhos. Para tentar captar o possível efeito de tais vieses, foi testada a inclusão de uma variável binária sobre a existência de filhos fora do lar na estimação. Não se observaram mudanças nos resultados e nem nos níveis de significância.

\section{Referências}

ALBERNAZ, A.; FERREIRA, F.; FRANCO, C. Qualidade e equidade no ensino fundamental brasileiro. Pesquisa e Planejamento Econômico, Rio de Janeiro, v. 32, n. 3, 2002.

ALVES, F. Escolhas familiares, estratificação educacional e desempenho escolar: quais as relações? Dados: Revista de Ciências Sociais, Rio de Janeiro, v. 53, n. 2, p. 447-468, 2010.

ALVES, J. E. D.; CAVENAGHI, S. Transições urbanas e da fecundidade e mudanças dos arranjos familiares no Brasil. Cadernos de Estudos Sociais, Recife, v. 27, n. 2, p. 91-114, 2012.

ASTONE, N. M.; MCLANAHAN, S. S. Family structure, parental practices and high school completion. American Sociological Association, Washington, v. 56, n. 3, p.309-320, jun. 1991.

BARROS, R. P.; FOX, L.; MENDONCA, R. S. Female-headed households, poverty and the welfare of children in urban. Economic Development and Cultural Change, Chicago, v. 45, n. 2, p. 231257, 1997.

BARROS, L. F. W.; ALVES, J. E. D.; CAVENAGHI, S. Novos arranjos domiciliares: condições socioeconômicas dos casais de dupla renda e sem filhos (Dinc). In: XVI ENCONTRO NACIONAL DE ESTUDOS POPULACIONAIS. Anais... Caxambu: Abep, 2008.

BECKER, G.; TOMES, N. An equilibrium theory of the distribution of income and intergenerational mobility. Journal of Political Economy, Chicago, v. 87, n. 6, p. 1153-89, 1979.

BECKER, G. S. A treatise on the family. Cambridge, MA: Harvard University Press, 1993.

BEHRMAN, J. R.; POLLAK, R. A.; TAUBMAN, P. Do parents favor boys? International Economic Review, Nova Jersey, v. 27, n. 1, p. 33-54, 1986.

BERQUÓ, E.; GARCIA, S.; OLIVEIRA, M. C.; LIVI-BACCI, M. Segunda transição demográfica no Brasil? Significados e enigmas. Demografia em Debate, v. 4, p. 135-156, 2012.

BOURDIEU, P. A reprodução. Rio de Janeiro: Francisco Alves, 1992.

BREEN, R.; JONSSON, J.O. Inequality of opportunity in comparative perspective: recent research on educational attainment and social mobility. Annual Review of Sociology, v. 31, p. 223-243, 2005. 
CAMERON, A. C.; TRIVEDI, P. K. Microeconometrics using stata. College Station, TX: Stata Press, 2009.

CARVALHO, S. C. de; KASSOUF, A. L. As despesas familiares com educação no Brasil e a composição de gênero do grupo de irmãos. Economia Aplicada, Ribeirão Preto, v. 13, n. 3, p. 353-375, 2009.

CASTRO, J. A. de; VAZ, F. M. Gastos das famílias com educação. In: SILVEIRA, F. G.; SERVO, L. M.; MENEZES, T.; PIOLA, S. F. (Ed.). Gasto e consumo das famílias brasileiras contemporâneas. Brasília: Instituto de Pesquisa Econômica Aplicada - Ipea, 2007. p. 77-104.

COLEMAN, J. S. Social capital in the creation of human capital. American Journal of Sociology, Chicago, v. 84, Supplement, p. S95-S120, 1988.

COLEMAN, J.; HOFFER, T. Public and private high schools. New York: Basic Books, 1987.

COLEMAN, J.; HOFFER, T.; KILGORE, S. High school achievement: public, catholic, and private schools compared. New York: Basic Books, 1982.

CURI, A. Z.; MENEZES-FILHO, N. A. Determinantes dos gastos com educação no Brasil. Pesquisa e Planejamento Econômico, Rio de Janeiro, v. 40, n. 1, p. 1-39, 2010.

EJRNES, M.; PORTNER, C. C. Birth order and the intrahousehold allocation of time and education. Review of Economics and Statistics, Cambridge, MA, v. 86, n. 4, p. 1008-1019, 2004.

EMERSON, P. M.; SOUZA, A. P. Birth order, child labor, and school attendance in Brazil. World Development, Amsterdam, v. 36, n. 9, p. 1647-1664, 2008.

EMERSON, P. M.; PORTELA SOUZA, A. Bargaining over sons and daughters: child labor, school attendance and intra-household gender bias in Brazil. Nashiville, TN: Vanderbilt University, 2002.

FERRÃO, M. E.; BELTRÃO, K. I.; FERNANDES, C.; SANTOS, D.; SUAREZ, M.; ANDRADE, A. C. O SAEB - Sistema Nacional de Avaliação da Educação Básica: objetivos, características e contribuições na escola eficaz. Revista Brasileira de Estudos de População, v. 18, n. 1-2, p. 111-130, 2001.

FERREIRA, F. H.G. Education for the masses? The interaction between wealth, educational and political inequalities. Economics of Transition, Nova Jersey, v. 9, n. 2, p. 533-552, 2001.

FRANÇA, M. T. A.; GONÇALVES, F. O. de. Sistemas públicos de ensino fundamental e a perpetuação da desigualdade: democracia e qualidade educacional como promotoras de justiça social. Revista Brasileira de Estudos de População, v. 29, n. 2, p. 303-322, 2012.

FREITAS, N. C. Investimentos familiares em educação dos filhos no Brasil: o arranjo familiar importa? 2015. 109 f. Dissertação (Mestrado) - Programa de Pós-Graduação em Desenvolvimento Econômico, Universidade Federal do Paraná, Curitiba, 2015.

FONTES, M. B. Situação econômica de arranjos domiciliares monoparentais e biparentais no Brasil: uma análise orçamentária. 2014. 127 f. Tese (Doutorado) - Centro de Desenvolvimento e Planejamento Regional, Universidade Federal de Minas Gerais, Belo Horizonte, 2014.

FONTES, M. B.; WAJNMAM, S.; GUEDES, G. R. Arranjos mono(bi)parentais e sua estrutura orçamentária. Oikos: Revista Brasileira de Economia Doméstica, v. 27, n. 1, p. 5-30, 2016.

GARCIA, L. S.; RODARTE, M. M. S.; COSTA, P. L. Emancipação feminina e novos arranjos familiares nas regiões metropolitanas brasileiras entre as décadas de 1990 e 2000. IN: XIV ENCONTRO NACIONAL DE ESTUDOS POPULACIONAIS. Anais... Caxambu: Abep, 2004.

GINTHER, D. K.; POLLAK, R. A. Family structure and children's educational outcomes: blended families, stylized facts, and descriptive regressions. Demography, New York, v. 41, n. 4, p. 671-696, 2004. 
GIUBERTI, A. C.; MENEZES-FILHO, N. Discriminação de rendimentos por gênero: uma comparação entre o Brasil e os Estados Unidos. Economia Aplicada, Ribeirão Preto, v, 9, n. 3, p. 369-384, 2005.

GLOMM, G. Parental choice of human capital investment. Journal of Development Economics, Amsterdam, v. 53, n. 1, p. 99-114, 1997.

GOLDRING, E. B.; PHILLIPS, K. J. R. Parent preferences and parent choices: the public-private decision about school choice. In: ANNUAL MEETING OF THE AMERICAN EDUCATIONAL RESEARCH ASSOCIATION. Proceedings... California, abr. 2006.

GUSTAFSSON, S. S.; STAFFORD, F. P. Childcare, human capital and economic efficiency. In: PERSSON, I.; JONUNG, C. (Ed.). Economics of the family and family policies. London: Routledge, 1997. p. 107-122.

HALPERN, D. F. Public policy, work, and families: the report of the APA presidential initiative on work and families. Washington: American Psychological Association, 2004.

HECKMAN, J. J. Policies to foster human capital. Research in Economics, v. 54, n. 1, p. 3-56, 2000. HODDINOTT, J.; HADDAD, L; ALDERMAN, H. Testing competing models of intrahousehold allocation. In: HADDAD, L.; HODDINOTT, J.; ALDERMAN, H. (Ed.). Intrahousehold resource allocation in developing countries: models, methods, and policy. London: The Johns Hopkins University Press, 1997. p. 129-141.

IBGE - Instituto Brasileiro de Geografia e Estatística. Coordenação de Trabalho e Rendimento. Pesquisa Nacional por Amostra de Domicílios: síntese de indicadores-2015. Rio de Janeiro: IBGE, 2016.

Tendências demográficas: uma análise da população com base nos resultados dos Censos Demográficos 1940 e 2000. Rio de Janeiro: IBGE, 2007.

JIMENEZ, E.; LOCKHEED, M.; PAQUEO, V. The relative efficiency of private and public schools in developing countries. The World Bank Research Observer, Washington, DC, v. n. 2, p. 205-2018, 1991.

LANKFORD, R. H.; WYCKOFF, J. H. Primary and secondary school choice among public and religious alternatives. Economics of Education Review, Amsterdam, v. 11, n. 4, p. 317-337, 1992.

LAVINAS, L.; NICOLL, M. Atividade e vulnerabilidade: quais os arranjos familiares em risco? Dados - Revista de Ciências Sociais, Rio de Janeiro, v. 49, n. 1, p. 67-97, 2006.

LONG, J.; TOMA, E. The determinants of private school attendance, 1970-1980. The Review of Economic and Statistics, Cambridge, MA, v. 70, n. 2, p. 351-357, 1988.

LOUREIRO, P. R. A.; SACHSIDA, A.; MOREIRA, T. B. S. Is there discrimination among Brazilian Lawyers? A random-effects approach. Análise Econômica, v. 29, n. 56, p. 293-307, 2011.

LLOYD, C. B.; BLANC, A. N. N. K. Children's schooling in Sub-Saharan Africa: the role of fathers, mothers, and others. Population and Development Review, Nova Jersey, v. 22, n. 2, p. 265-298, 1996.

MACEDO, M. dos S. Mulheres chefes de família e a perspectiva de gênero: trajetória de um tema e a crítica sobre a feminização da pobreza. Caderno CRH, Salvador, v. 21, n. 53, p. 389-404, 2008.

MARTELETO, L. J. O papel do tamanho da família na escolaridade dos jovens. Revista Brasileira de Estudos de População, Belo Horizonte, v. 19, n. 2, p. 159-177, 2002.

MARTINEZ, E. Z. et al. Gravidez na adolescência e características socioeconômicas dos municípios do Estado de São Paulo, Brasil: análise espacial. Cadernos de Saúde Pública, Rio de Janeiro, v. 27, n. 5, p. 855-867, 2011. 
MEDEIROS, M.; OSORIO, R. G. Mudanças nas famílias brasileiras: a composição dos arranjos domiciliares no Brasil entre 1978 e 1998. Brasília: Ipea, 2002. (Texto para Discussão, n. 886).

MENEZES-FILHO, N.; PAZELLO, E. Does money in schools matter? Evaluating the effects of a funding reform on wages and test scores in Brazil. São Paulo: Universidade de São Paulo (USP), 2004.

MINAMIGUCHI, M. M. Monoparentalidade feminina no Brasil: dinâmica das trajetórias familiares. 2017. 152 f. Tese (Doutorado) - Centro de Desenvolvimento e Planejamento Regional, Universidade Federal de Minas Gerais, Belo Horizonte, 2017.

MONTALI, L.; LIMA, M. T. A divisão sexual do trabalho e a desigualdade no mercado de trabalho segundo gênero: implicações para a superação da pobreza. In: VII CONGRESSO LATINOAMERICANO DE ESTUDOS DO TRABALHO. Anais... São Paulo: Alast, 2013.

MORDUCH, J. Sibling rivalry in Africa. The American Economic Review, v. 90, n. 2, p. 405-409, 2000.

NOELL, J. Public and catholic schools: a reanalysis of "public and private schools". Sociology of Education, Washington, DC, v. 55, n. 2, p. 123-132, 1982.

OLIVEIRA, Z. L. C. de; MIRANDA-RIBEIRO, P.; LONGO, L. Uma exploração inicial das informações sobre família no Censo Demográfico de 2010. IN: XVIII ENCONTRO NACIONAL DE ESTUDOS POPULACIONAIS. Anais... Águas de Lindóia: Abep, 2012.

PALERMO, G. A.; SILVA, D. B. D. N.; NOVELLO, M. S. F. Fatores associados ao desempenho escolar: uma análise da proficiência em matemática dos alunos do $5^{\circ}$ ano do ensino fundamental da rede municipal do Rio de Janeiro. Revista Brasileira de Estudos de População, Rio de Janeiro, v. 31, n. 2, p. 367-394, jul./dez. 2014.

PHIPPS, S. A.; BURTON, P. S. What's mine is yours? The influence of male and female incomes on patterns of household expenditure. Economica, v. 65, n. 260, p. 599-613, 1998.

PINHEIRO, L.; GALIZA, M.; FONTOURA, N. Novos arranjos familiares, velhas convenções sociais de gênero: a licença-parental como política pública para lidar com essas tensões. Revista Estudos Feministas, Florianópolis, v. 17, n. 3, p. 851-859, 2009.

PORTELLA, A. L.; BUSSMANN, T. B.; OLIVEIRA, A. M. H. de. A relação de fatores individuais, familiares e escolares com a distorção idade-série no ensino público brasileiro. Nova Economia, v. 27, n. 3, p. 477-509, 2018.

SAMPAIO, B.; GUIMARÃES, J. Diferenças de eficiência entre ensino público e privado no Brasil. Economia Aplicada, Ribeirão Preto, v. 13, n. 1, p. 45-68, 2009.

SORJ, B. Trabalho e responsabilidades familiares: um estudo sobre o Brasil. Relatório final. Rio de Janeiro: UFRJ, 2004.

SOUSA, A. P. D. Estudo comparativo das famílias monoparentais masculinas e monoparentais femininas: a influência do genitor no desenvolvimento familiar. 2008. 171 f. Dissertação (Mestrado) - Faculdade de História, Direito e Serviço Social, Universidade Estadual Paulista, Franca, 2008.

TAUBMAN, P. Role of parental income in educational attainment. The American Economic Review, Pittsburgh, PA, v. 79, n. 2, p. 57-61, 1989.

THOMAS, D. Like father, like son; like mother, like daughter: parental resources and child height. Journal of Human Resources, Madison, WI, v. 29, n. 4, p. 950-988, 1994.

WOOLDRIDGE, J. M. Introdução à econometria: uma abordagem moderna. São Paulo: Thomson Learning, 2006. 


\section{Sobre os autores}

Júlia Sbroglio Rizzotto é mestranda no Programa de Pós-Graduação em Economia do Desenvolvimento na Pontifícia Universidade Católica do Rio Grande do Sul (PUCRS).

Marco Túlio Aniceto França é doutor em Desenvolvimento Econômico pela Universidade Federal do Paraná (UFPR). Professor adjunto no Programa de Pós-Graduação em Economia do Desenvolvimento na Pontifícia Universidade Católica do Rio Grande do Sul (PUCRS).

Gustavo Saraiva Frio é doutorando no Programa de Pós-Graduação em Economia do Desenvolvimento na Pontifícia Universidade Católica do Rio Grande do Sul (PUCRS) e mestre em Economia Aplicada pelo Programa de Pós-Graduação em Organizações e Mercados (PPGOM) pela Universidade Federal de Pelotas (UFPel).

\section{Endereço para correspondência}

Júlia Sbroglio Rizzotto

Av. Ipiranga, 6681, Prédio 50, Partenon

90619-900 - Porto Alegre-RS, Brasil

Marco Túlio Aniceto França

Av. Ipiranga, 6681, Prédio 50, Partenon

90619-900 - Porto Alegre-RS, Brasil

Gustavo Saraiva Frio

Av. Ipiranga, 6681, Prédio 50, Partenon

90619-900 - Porto Alegre-RS, Brasil

\section{Abstract}

Do family arrangements affect parents' decision of school for their children?

This study aims to analyze whether family arrangements (single-parent or two-parent) influence the choice of school system (public or private) for children. For this analysis, data from the 2015 National Household Sample Survey (PNAD) were used. Results point to dissimilarities among family arrangements which can be explained by differences in individual preferences as well as in family income. We found that families are more likely to invest privately in early childhood education. The evidence may be due to the small number of public day care centers. According to the order of birth, families can invest in their eldest child to the detriment of their other children, in the case of female single-parent and two-parent family arrangements. In addition, we found that male children were less likely to study in a private school in female single-parent arrangement. This result may show mothers' wishes to encourage daughters to study in an attempt to empower them.

Keywords: Family arrangement. School network. Logit. Birth order. 


\section{Resumen}

¿Importan los arreglos familiares a la hora de decidir en qué red de enseñanza matricular a los hijos?

El objetivo de este trabajo es analizar si los arreglos familiares (monoparentales o biparentales) afectan la elección parental del tipo de institución (pública o privada) en la cual serán matriculados los hijos. Para este analísis fueron utilizados los datos tomados de la Pesquisa Nacional por Amostra de Domicílios (PNAD) de 2015. Los resultados apuntan a que las diferencias en la conformación de las familias pueden ser explicadas por las preferencias de los individuos así como por su enta familiar. Se observa que existe mayor probabilidad de que las familias inviertan en educación privada durante la educación infantil. No obstante, esto puede deberse a la falta de oferta de este servicio en la red de instituciones públicas. Asimismo, de acuerdo al orden de los hijos, se prefiere invertir en el hijo mayor en detrimento de los demás hijos, especialmente los arreglos familiares monoparentales femeninos o biparentales en matrimonio. A su vez, se encontró que el hijo de sexo masculino tiene menos oportunidades de estudiar en una institución privada en una familia con arreglo monoparental femenino. Este resultado puede evidenciar la preferencia de la madre a incentivar el estudio en la hija mujer, en una tentativa de buscar su empoderamiento.

Palabras clave: Estructura familiar. Instituciones de educación. Logit. Orden entre hermanos.

Recebido para publicação em 25/10/2018

Aceito para publicação em 10/12/2018

\section{ANEXO}

Análise de componentes principais

\begin{tabular}{ccc}
\hline Variáveis & KMO & Uniqueness \\
\hline Celular & 0,743 & 0,793 \\
TV por assinatura & 0,776 & 0,645 \\
Acesso à internet & 0,728 & 0,488 \\
Carro & 0,729 & 0,545 \\
Máquina de lavar & 0,713 & 0,468 \\
\hline
\end{tabular}

Fonte: IBGE. Pesquisa Nacional por Amostra de Domicílios - PNAD 2015. Elaboração dos autores. 